\title{
Residential Energy
} Efficiency Research Planning Meeting Summary Report

Washington, D.C. - October 27-28, 2011

February 2012 


\begin{abstract}
NOTICE
This report was prepared as an account of work sponsored by an agency of the United States government. Neither the United States government nor any agency thereof, nor any of their employees, makes any warranty, express or implied, or assumes any legal liability or responsibility for the accuracy, completeness, or usefulness of any information, apparatus, product, or process disclosed, or represents that its use would not infringe privately owned rights. Reference herein to any specific commercial product, process, or service by trade name, trademark, manufacturer, or otherwise does not necessarily constitute or imply its endorsement, recommendation, or favoring by the United States government or any agency thereof. The views and opinions of authors expressed herein do not necessarily state or reflect those of the United States government or any agency thereof.
\end{abstract}

Available electronically at http://www.osti.gov/bridge

Available for a processing fee to U.S. Department of Energy and its contractors, in paper, from:

U.S. Department of Energy

Office of Scientific and Technical Information P.O. Box 62

Oak Ridge, TN 37831-0062

phone: 865.576 .8401

fax: 865.576.5728

email: mailto:reports@adonis.osti.gov

Available for sale to the public, in paper, from:

U.S. Department of Commerce

National Technical Information Service

5285 Port Royal Road

Springfield, VA 22161

phone: 800.553 .6847

fax: 703.605 .6900

email: orders@ntis.fedworld.gov

online ordering: http://www.ntis.gov/ordering.htm 


\title{
Residential Energy Efficiency Research Planning Meeting Summary Report
}

\author{
Prepared for: \\ Building America \\ Building Technologies Program \\ Office of Energy Efficiency and Renewable Energy \\ U.S. Department of Energy
}

Prepared by:

National Renewable Energy Laboratory

1617 Cole Boulevard

Golden, CO 80401

February 2012 
[This page left blank] 


\section{Contents}

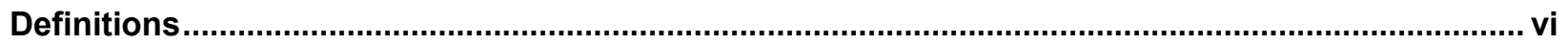

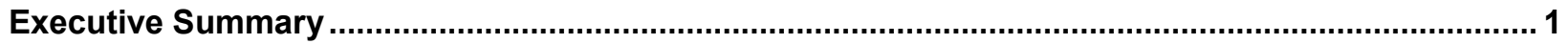

1 Welcome Remarks - Ren Anderson, National Renewable Energy Laboratory .......................... 2

2 U.S. Department of Energy Update - Samuel Rashkin, Chief Architect, Building Technologies

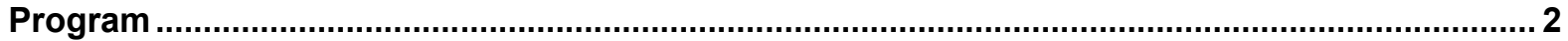

3 Space Conditioning Standing Technical Committee Presentation ........................................... 5

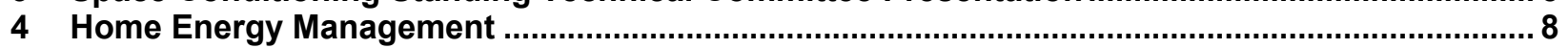

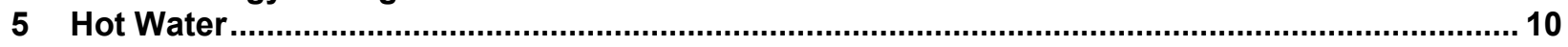

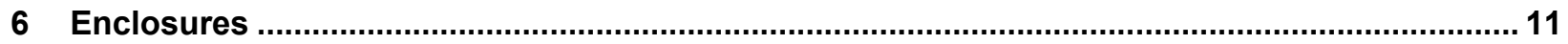

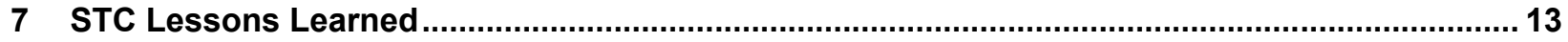

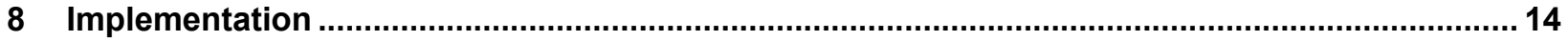

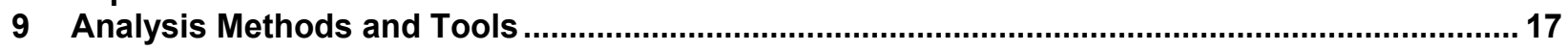

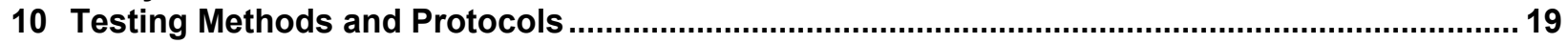

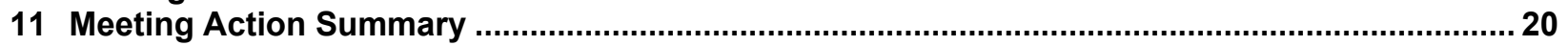




\section{Definitions}

ACCA

$\mathrm{ACI}$

ARBI

ARIES

ASHRAE

BA

BA-PIRC

BARA

BB

BC

BIRA

BPI

BSC

BTP

CARB

CEER

DOE

EPRI

FSEC

GTI

LBNL

NAHB-RC

NELC

NIST

NREL

NSTAR

NEEA

NYSERDA

ORNL

PARR

PNNL

RESNET

SIP

TVA

WSU
Air Conditioning Contractors of America

Affordable Comfort, Inc

Alliance for Residential Building Innovation

Advanced Residential Integrated Energy Solutions

American Society of Heating, Refrigerating and Air-Conditioning Engineers

Building America

Building America Partnership for Improved Residential Construction

Building America Retrofit Alliance

BetterBuildings

Builders Challenge

Building Industry Research Alliance

Building Performance Institute

Building Science Corporation

Building Technologies Program

Consortium for Advanced Residential Buildings

Cost Effective Energy Retrofit

U.S. Department of Energy

Electric Power Research Institute

Florida Solar Energy Council

Gas Technology Institute

Lawrence Berkeley National Laboratory

National Association of Home Builders Research Center

National Energy Leadership Corps

National Institute of Standards and Technology

National Renewable Energy Laboratory

NorthernSTAR Building America Partnership

Northwest Energy Efficiency Alliance

New York State Energy Research and Development Authority

Oak Ridge National Laboratory

Partnership for Advanced Residential Retrofit

Pacific Northwest National Laboratory

Residential Energy Services Network

Structural Insulated Panel

Tennessee Valley Authority

Washington State University 


\section{Executive Summary}

The 2011 Residential Energy Efficiency Research Planning Meeting was held October 27 and 28, 2011, in Washington D.C. The meeting brought together representatives from the U.S. Department of Energy's (DOE) Building America research teams, national laboratories, and the DOE to focus on research planning activities for 2013 and 2014.

Presenters were chairs from the Building America Standing Technical Committees (STC), who included:

- Ben Polly (NREL), chair of the Analysis Methods and Tools STC

- Dane Christensen (NREL), chair of the Testing Methods and Protocols STC

- Deane Evans (BARA) and Stacy Hunt (BARA), co-chairs of the Implementation STC

- Eric Martin (FSEC), chair of the Space Conditioning STC

- Katie Boucher (BSC), chair of the Enclosures STC, and Chris Schumacher (BSC)

- Kurt Roth (Fraunhofer) and Olga Sachs (Fraunhofer), chairs of the Home Energy Management STC

- Marc Hoeschele (ARBI), chair of the Hot Water STC.

Presentations focused on capturing priorities within each STC's work that will best assist in overcoming technical challenges and delivering Building America research results to the market. Presenters discussed priorities that will be fully addressed in 2011 and 2012 program work, those that will be partially addressed, and those that have no projects that directly address them. This information was submitted to assist DOE, national laboratories, and Building America teams in research planning for future work.

The intent of this report is to capture key points in the STC presentations and discussions, namely to call out additional projects that were identified by the audience as currently addressing STC priorities, and to identify additional work that is not currently being focused on or organizations capable of undertaking priorities.

\section{Acknowledgements}

The authors would like to thank the U.S. Department of Energy for hosting the meeting that is summarized in this report. We would also like to acknowledge the contributions of the Standing Technical Committee chairs for their work in conducting the meeting. Finally, a special thanks to Confluence Communications for providing invaluable assistance to NREL in the production of the meeting and this report. 


\section{Welcome Remarks - Ren Anderson, National Renewable Energy Laboratory}

Ren Anderson introduced the meeting and stressed that the focus of the sessions would be in integrating planning processes between the U.S. Department of Energy (DOE), national laboratories, and Building America (BA) Standing Technical Committees (STCs) for 2013 and beyond. He emphasized that this process can seem awkward to those not familiar with the budget process because work for 2012 is not yet finalized while we are focusing on budgetary planning processes for future years. However, this process is necessary to provide valid technical input at the right times to ensure that projects are properly incorporated into future budgets.

\section{U.S. Department of Energy Update - Samuel Rashkin, Chief Architect, Building Technologies Program}

Sam Rashkin's major function at the DOE is as program and policy advisor with a focus on linking research to industry. His update addressed latest developments affecting the BA teams.

Sam pointed out that key metrics for program success are currently being considered by the DOE team and proposed enhancing the current percentage of energy savings metric with how much value is delivered to stakeholders. He then summarized the six key value propositions provided by $\mathrm{BA}$ as identified by the DOE team:

1. Innovations have been developed that transform how we build houses in this country. However, many of the innovations get buried in research reports. BA needs a major initiative to tell this story better.

2. Guidance is provided with best practice guides, the measures cost database, and a new DOE Resource Tool.

3. Proven performance is established with case studies and publications. The content serves as a valuable tool for demonstrating technical and business results needed to influence decision-makers and code officials to embrace high-performance measures.

4. Technical assistance is provided directly to key partners and through a wide variety of training options.

5. Recognition is provided through the Builders Challenge label and linkages to ENERGY STAR $^{\circledR}$ Qualified Homes.

6. Research tools have been developed and then shared with industry. This includes the new Field Test Guide, a unique reference document for measurement and evaluation, and BEopt software for optimizing the energy efficiency performance of new homes.

Sam suggested that the current BA website does not have a clear focus and could instead much more clearly associate BA with world-class research that delivers peak energy performance solutions for better American homes. This includes highlighting and providing one-click linkages to each of the six value propositions discussed above. 
Sam provided more detail about the innovation initiative at the DOE to tell the BA story with a clear message focused on top innovations from the program and demonstrating a business case of the connection between better building science and good bottom-line sense. The focus of this story will be on transformational results. The DOE plans to have a major marketing event to showcase innovations that have come from BA since it started and then have annual events to highlight the most significant innovations for that year.

Christine Barbour pointed out that ideas for these top innovations would be posted on the wall during the meeting for attendees to add to and vote on.

Sam went on to talk about a new case study template for BA, focused on promoting proven performance and providing as much evidence as possible that a participant should move ahead and adopt new innovations. The new template will provide a quick way to find project information. All case studies will be linked to the new Resource Tool.

Sam discussed the use of the BA logo and new logo use guidelines to ensure that the use does not imply DOE endorsement of a builder or a builder's product. BA is a research program and participants should be able to use the logo to promote their participation in the program but not to imply that a product meets certain criteria.

Sam discussed the new DOE Resource Tool project, which will provide a "Dewey decimal system" for accessing building science information with a simple drill-down approach that avoids the current maze of information. Three interfaces will be developed, including a building science flow chart, a building component flow chart, and ENERGY STAR checklists. The tool will be initially populated with content from the ENERGY STAR for Homes Version 3 Field Guides and then augmented with details from BA content. This will ensure the initial release of the Resource Tool provides comprehensive building science solutions for users. As additional BA research results are developed, they will be added so the tool is continually improved. This initiative is also working with the information technology team at the DOE headquarters that is developing mobile applications so the content can be accessed via mobile devices.

Sam discussed the Builders Challenge (BC) and a new format/construct for the initiative that will align with ENERGY STAR to resolve current conflicts. This begins with a requirement under the new version of the BC that all homes must comply with ENERGY STAR for Homes Version 3. In addition, $\mathrm{BC}$ will adopt a similar Reference Design and variable HERS Index Score threshold. New mandatory requirements are also included such as WaterSense, Indoor airPLUS, and Renewable Energy Ready Home checklists. The new version will also encourage quality management and disaster resistance techniques. The initiative will still be called the Builders Challenge, but there are discussions about calling it the ENERGY STAR Builders Challenge. Once BC criteria are met, a home achieves peak energy performance and is now ready for renewable energy integration. Builders around the country who consistently meet the BC criteria have found a "sweet spot" at five to 25 homes per year. Sam wants to share with the wider production builder industry the business case for similarly providing a subset of their homes at this peak performance level including no callbacks, no need for marketing because of word of mouth, and high profit margins. This business case message will be the focus of builder recruitment. 
The audience raised a series of questions after Sam's presentation:

Subrato Chandra with PNNL suggested that the top innovations story was going to be a big deal for the program and recommended that the DOE not rush the development of the story by focusing on it during the meeting. He suggested that a follow-up effort be undertaken to allow the audience to digest the information and revisit it later, for best results. Max Sherman with LBNL concurred.

Jan Kosny with Fraunhofer said that he is excited by the special focus on innovation and sees BA as the best tool for the U.S. industry to show technologies and strategies that may be considered innovative here but have been used with proven results in Europe and other countries for many decades and in production environments.

Subrato Chandra with PNNL also suggested that we not link ENERGY STAR to the Builders Challenge, that this strategy would dilute the value of the increased energy performance offered by BC homes. He asked "how do you differentiate a 20-year-old home with the ENERGY STAR label and a Builders Challenge home if they are labeled one and the same?" Sam responded that the thought was likened to the idea of having different levels of performance associated with the same manufacturer such as Toyota and Lexus.

Mark Berman with ARBI suggested that we utilize the ENERGY STAR brand, but perhaps downplay it.

Stacy Hunt with BARA asked the audience to consider that in recent studies, more than $85 \%$ of consumers know the ENERGY STAR brand. She suggested that if our goal is market transformation, and knowing that BA budgets will likely never be adequate to do significant brand development efforts, we should utilize the brand awareness and outreach budget of ENERGY STAR to reach the largest portion of the market possible.

Emanuel Levy with ARIES suggested that we run a risk if we don't link the two that they would be in competition.

Eric Werling with the DOE suggested that the audience continue to think about this issue and broaden perspectives to include the possibility for an initiative to capture the retrofit market, as $\mathrm{BC}$ will continue to focus only on new construction in the short term. 


\section{Space Conditioning Standing Technical Committee Presentation}

Eric Martin (FSEC), chair of the Space Conditioning STC, presented on current STC priorities and asked for suggestions from the audience on items missing from the prioritization and project list.

The following list contains any key priorities, missing projects, and next actions identified during the session. For complete details and status on priorities of this STC, please see the presentation.

\section{Dehumidification}

- Determination of Total Internal Moisture Gains in Homes - there are no projects listed that address this gap, but Iain Walker with LBNL suggested that we do know the answer to this question and the range is "very big."

- Protocol to Assess and Correct Deficiencies in RH Control in Homes - Eric noted that they received lots of input when talking about RH control in new or existing homes, when you don't want to automatically go to supplemental dehumidification. There is a need for protocol to guide process of correcting deficiencies and looking at improvements to primary heating and cooling before supplemental dehumidification. BSC has proposed to develop this improvement recommendation. BA-PIRC work is working on moisture and air flow.

- Need a Metric for Acceptable RH in Homes - there are no projects identified in this priority area, but it needs to be a priority over the next few years. Michael Lubliner with WSU responded that ASHRAE is currently funding a research project that may address this and that results will be presented at ACI in Baltimore, which would be a good time for an expert meeting. It was also identified that there is a need to create a complete model of BEopt and Energy Plus with RH included.

- Accurate Simulation/Prediction of RH in Homes - Jan Kosny noted that there is no complete BEopt model with RH. There is a need for projects to address improvements in RH sensors/controllers. A suggestion was made to have ENERGY STAR dehumidification systems be required to report performance.

- Adjustments/Enhancements to Primary HVAC Systems for Improved RH Control - The EPA has been engaged in discussions, looking at ENERGY STAR HVAC specifications, but a metric is needed to compare dehumidification performance of different systems that might include different technologies. The EPA indicated that as they engage the industry, the industry is asking what the value is and how to communicate to consumer. It's not enhanced energy efficiency. CARB has a future test house looking at supplemental dehumidification and the issue of energy efficiency. Eric noted that this priority could be lowered, but we should revisit it as BA homes continue to evolve as loads are reduced. However, other attendees noted that there are possible building failures being observed in the field due to interior and exterior moisture and, for that reason, this priority needs to be addressed. Phil Fairey noted that there was a large study by BSC in Houston that shows that for a number of hours a year, RH goes above $60 \%$. 
- Need to Understand Operating Performance of Existing and Emerging Supplemental Dehumidification Equipment - this priority was added during the discussion - a report by Dane Christensen was referenced.

\section{Distribution Systems}

- Need for Cost Effective Assessment Methods to Determine When to Repair Ducts - both PARR and BA-PIRC had projects that potentially address parts of this priority. The NAHB-RC project listed should be removed, as they are not pursuing it in 2012. Also, NELC has a 2011/2012 study that should be included.

- Need for Cost Effective Methods to Conduct Repair/Replacement of Leaky and Poorly Insulated Ducts - an NELC study for 2011/2012 was added to the list of projects during discussion.

- Need for Cost Effective Methods to Repair/Replace-ARBI added that they will be conducting a webinar on hydronic distribution and that they are working on improving efficiency by eliminating ducts. There was a suggestion that there is a need to study zoning systems and modeling for multi-split systems

- Need Low Cost Space Conditioning Distribution Strategies for Low Load Homes -PARR added that they have a lot of research work going on in this area that should be incorporated.

- Lack of Knowledge on (Distribution) Performance of Ductless Systems as an Alternative to Ducted Systems - ARBI is looking at ductless hydronic systems and the distribution of temperature comfort parameters. Fraunhofer is doing that in some test homes looking at mini-splits - monitoring comfort in rooms and detailed performance conditions. BAPIRC is looking at existing homes with ductless mini-splits and comparing them to a central system. BIRA and ORNL are also looking at mini-splits.

- How Should Zoning Be Handled in High Performance Homes? It was noted that ARBI has projects looking at mixed mode distribution and that NREL data and field data indicate that zoning issues are significant. ORNL spent a year working on multi-split systems. There is a non-BA NIST study and a need for work on modeling under this priority.

\section{Ventilation and IAQ}

- How Tight is Too Tight? Attendees suggested that a long term study may be a good idea here.

- Combustion Safety in Tight Houses - it was noted that in addition to the current work identified by the STC, BPI and RESNET are rewriting combustion safety guidelines.

- Should Ventilation Air be Evenly Distributed/What is the Source of Ventilation Air? Additional gaps in addressing the priority included getting a handle on contaminant issues. No projects were added during the discussion. 


\section{Heating and Cooling Equipment}

- Modifications to Existing Standards for Rating Equipment Efficiency, or New Standards that Communicate Installed Performance - a need for better communication of field performance was identified as well as the need to look at the rulemaking and standards modification process to ensure that BA knowledge is properly incorporated. In addition, there was a suggestion to expand this topic to look at HRV/ERV standards, which don't meet the rated specifications.

- Optimization of Hybrid Heating System Transition Points - the following projects were added during the discussion: One group is looking at options for dual-fuel systems vs. other methods such as air sealing; ACCA is updating Manual S and the information from this research may help inform this priority; the ability to model hybrid systems in BEopt is needed; performance curves for evaporative coolers input into BEopt are needed.

- Evaporatively Cooled Condensers - ARBI has been working with NREL to get evaporatively cooled condensers into BEopt. There is a need for methods, techniques, and tools to improve efficiency of existing equipment in-situ.

\section{Other}

- Radiant Cooling for Off Peak Cooling Project, ARBI - this project was added during the discussion. 


\section{Home Energy Management}

Kurt Roth (Fraunhofer) and Olga Sachs (Fraunhofer), chairs of the Home Energy Management STC, presented on current STC priorities and asked for suggestions from the audience on items missing from the prioritization and project list.

The following list contains any key priorities, missing projects, and next actions identified during the session. For complete details and status on priorities of this STC, please see the presentation.

Projects added throughout the discussion (may apply to multiple priority categories):

- NELC research on how smartphone apps open up door to social media.

- Suggestion to look at this issue from a systems integration point of view, rather than an individual technology point of view.

- Suggestion that we have to assume keeping the human in the loop is important.

- Suggestion that we further discuss the subtopic of how HEM devices interface with other home issues (interface with audit maybe).

- Suggestion that there is a need to influence manufacturers as well.

- Suggestion that there needs to be advice provided along with feedback devices.

- Suggestion that there is a need for a large statistical sample and to have teams test a few approaches.

- Suggestion that behavior research is covered by industry and BA should focus on technology.

- There is a possible IBACOS study on behavior in military-base housing.

- ARBI study on performance guarantees.

- Study on not needing thermostat setbacks.

- Non-BA emerging technologies study on thermostat setbacks.

- ORNL project with TVA: looking at peak loads in deep energy retrofits; whole house management system and then energy efficiency upgrades.

- LBNL is looking at wireless water and gas end use monitoring.

- Suggested project to compare ducts in and out of conditioned space and see whether setbacks are used.

- Possible ORNL study on water heater communications - unknown status.

- BA-PIRC/GTI project on natural gas feedback.

- Non- BA Lubliner project with NIST looking into fault detection devices for HVAC.

- BIRA CSI combined system with solar study.

- Hybrid study by BIRA.

- Lubliner study on military housing baseline behavior. 
- Possible addition of study on screening process for finding problem homes.

- Suggested research on how to create motivation for using the technologies.

Other projects added at the end of the meetings under HEM:

- BIRA project on the flat load curve. May have HEM plus smart grid issues as well as return on investment implications.

- ARBI project with behavioral aspects from last year collecting energy use data from a student occupied building. Central metering but each unit has energy display. We see behavioral aspects.

- ARIES project with 190 apartments with Internet enabled room A/C - behavioral data on fleet controlled $\mathrm{A} / \mathrm{C}$.

- NStar project with local utility: 450 customers with TED displays being compared with thousands of O-Power users and a control group.

- Non-BA PNNL and the gridwise program in residences and displays. Contact Graham Parker for info.

- There is an expert meeting on behavior, December 2 from 2-5pm in Washington, D.C.

The following additional key points were observed:

- With devices, if you don't create pain, emotion, or incentive, what will get people to use these technologies? This is a future research need. We may be doing research on obsolete technologies.

- Need to leverage non-energy benefits.

- Might consider coupling HEM with proximity awareness with GPS and smartphones.

- There is a clear need to keep existing homes, new homes, code homes, and high performance homes distinct in this research - different strategies and different return on investment for each. 


\section{Hot Water}

Marc Hoeschele (ARBI), chair of the Hot Water STC, presented on current STC priorities and asked for suggestions from the audience on items missing from the prioritization and project list. The following list contains any key priorities, missing projects, and next actions identified during the session. For complete details and status on priorities of this STC, please see the presentation.

High Efficiency Combined Hydronic System Performance and Cost Impacts - NSTAR has a project retrofitting several hundred homes and monitoring the performance. BSC has a project monitoring hydronic systems. WSU noted that they are working with Pierce County Habitat for Humanity on a project that has several of these systems.

- HPWH Performance (Isolate Behavior Impacts on Performance) - there is an EPRI field study of 170 homes that will provide a short-term read on customer satisfaction. NEEA is starting a field guide for heat pumps in cold and marine climates. There is a need for a bigger sample of HPWH use, behavior, and impacts of reduced load on HPWH performance. It was suggested that we look to European studies for thermal heat storage, where much work has already been done.

- Collect a Broad, Uniform Set of Hot Water Usage Data and Associated Demographic Data - Fraunhofer noted that they have a project with 190 apartments where they have data and could get information on patterns, loads, and usage quantities. It was noted that a hot water database is being put together by Jim Lutz at LBNL. A need to partner with utility programs was identified. Southern Company has a field test that may be relevant to this work. Better detailed hot water use data is needed to drive simulation models for designing efficient water heating systems for single and multifamily buildings.

- Track Maintenance/Reliability/Customer Acceptance Issues on Emerging Technologies (Gas Tankless, HPWH, Hybrid Systems, Demand Recirculation, Etc.) - it was identified that we need larger field studies on customer acceptance and maintenance issues. Utilities running programs may be a resource to pursue.

- Validate HPWH, Tankless, Condensing Storage, Hybrid Models with Lab/Field DataBA-PIRC, NREL, NELC, and CARB all have projects in this area.

- Integrate Detailed Modeling Tools - it was noted that Jim Lutz of LBNL works in this area. Additionally, NREL is completing a study of heat pump water heaters to identify where these could replace existing gas or electric water heaters. 


\section{Enclosures}

Katie Boucher (BSC), chair of the Enclosures STC, and Chris Schumacher (BSC) presented on current STC priorities and asked for suggestions from the audience on items missing from the prioritization and project list.

The following list contains any key priorities, missing projects, and next actions identified during the session. For complete details and status on priorities of this STC, please see the presentation.

\section{Walls}

- Thermal Bridging in Residential Codes - it was noted that American and European builders are speaking two different languages and there is a need to educate the U.S. market on U-values to mirror the European market.

- Vapor Impermeable Exterior Insulating Sheathing - it was noted that non-wood based composite sheathing materials should also be addressed. There is an ORNL report being released in March 2012 that will cover this type of work in Charleston, SC. CEER is also working on this topic in their lab homes.

- Moisture Management Limits for High-R Walls - CEER and NAHB-RC are working to place several monitors within the same wall to see specific changes and get more detailed readings. Fraunhofer has southern climate research on this topic underway.

- Cladding Attachments over Thick Exterior Insulating Sheathing - NAHB-RC is working on the wind testing aspects of this topic.

- Risk Assessment Techniques for Adding Exterior Insulation - NAHB-RC is doing work in the lab on this topic and is hoping to put together a simple spreadsheet for builders.

- $\quad$ Structural Performance, Wind Pressure, and Bracing Options for New Wall Systems NAHBRC noted that they have a research report in this area to share.

- $\quad$ Moisture Performance of Wall Systems - CEER noted that they will be monitoring for retrofit packages.

- Fire Resistance Rating of High R-value Wall Assemblies - ORNL noted that CERC is working with China this year. There is a big code fight about this.

- Insulating and Air Sealing Inaccessible Places - ORNL has a report available on this topic.

- Advanced Envelope Options for Factory Built - ARIES has worked in this area.

\section{Roofs}

- Spray Polyurethane Foam Under Plywood and OSB Roof Decks - ORNL noted work in this area in Charleston, S.C., with several types of SPF.

- Unvented Attic with Spray Foam with Existing Attic Floor Insulation - PNNL is working on a project that uses SPF in existing sealed attics. It was noted that perhaps BA should develop IAQ protocol and that the environmental footprint of manufacturing foams verses the overall energy savings of using foams should be considered. 


\section{Foundations}

- Foundations: Basement Slab and Slab on Grade Heat Loss - IBACOS noted a potential project with 80 sensors in a New York home. NSTAR noted three small projects

currently underway, including an update of the foundation design handbook with ORNL.

\section{Materials}

- Materials: SIPs - NAHB-RC noted a project with NYSERDA focused on use of SIPs for retrofits.

- Flame Spread Ratings for Foam Plastic - It was noted that in some other countries this has been addressed and the focus is not flame spread but fumes.

\section{Air Tightness}

- Airtightness Strategies - A CEER lab home project was noted.

- Relative Contributions of Air Leakage Paths - IBACOS is working on a related project in New York as is Newport Partners. CEER is working on a related project with sequential side-by-side testing. ORNL is doing this using incremental types of testing.

\section{Other}

- Sequencing and Phased Retrofits - CEER is working on a project focused on air sealing, insulation, and HVAC in retrofits and measuring the sequence of events. The ultimate goal will be a guideline and then into a format that people can use. 


\section{STC Lessons Learned}

Mike Gestwick with NREL presented "lessons learned" from the BA Standing Technical Committee management process from 2011, as this was the first year implementing the STCs. Because the process is new, STC chairs have all had a different approach. The goal is that, moving forward, all STCs converge on similar processes.

The following topics were discussed:

- The voting process, for prioritizing topics within STCs, was varied. Mike noted that voting and prioritization should be done on significance of a gap while omitting cost/level of effort. Attendees expressed some concern that the number of people voting was too low and indicated not enough involvement. There was an interest in getting a larger mix of stakeholders involved in the committees to create input from outside of our research group. Anonymity was claimed as important, rather than identifying who is voting in each STC; however, it was suggested that company type might be useful information to gather. It was noted that STCs need a process for determining that a priority has been fully addressed.

- STC involvement and promotion: Attendees noted that it was difficult to get people to participate and agreed that there is an awareness issue and we need to do a better job of promoting the role of the STCs and how to become involved to the industry.

- It was suggested that a "super committee" of STC chairs be put together to create and roll out a common process and to encourage cross-STC communication.

- How priorities are identified, added, determined as complete, and maintained should be standardized.

- Need consistent "granularity" with respect to how gaps are defined and characterized.

- Need more explicit guidance to force consistency.

A follow-up document will be produced by NREL capturing the process for managing STCs moving forward. 


\section{Implementation}

Deane Evans (BARA) and Stacy Hunt (BARA), co-chairs of the Implementation STC, presented on current STC priorities and asked for suggestions from the audience on items missing from the prioritization and project list.

The following list contains any key priorities, missing projects, and next actions identified during the session. For complete details and status on priorities of this STC, please see the presentation.

- Outreach Plan for Building America - the BetterBuildings (BB) program is doing significant work in this area and Dale Hoffmeyer (DOE) is charged with developing a DOE communications plan. It was suggested that BA research ways to motivate homeowners.

- Value-Stream Map of the Retrofit Process - it was identified that PARR has a project in this area and that there is a DOE/Booz Allen Hamilton report on retrofit business models.

- Continuous Learning Mechanisms for Contractors to Transition to Energy Efficient Design/Construction - ORNL has a major project with private industry and contractors working through electric utilities for mechanisms for retrofits. ARBI is working on retrofit contractor infrastructure projects. LBNL is working with BPI and RESNET to adjust training and certification for contractors and a new pro version of Home Energy Saver. BetterBuildings was mentioned as having a huge experiment of deployment and, along with the Home Energy Score, should be included. There is a PNNL project specifically developed for weatherization contractors transitioning to home performance contractors. A BA-PIRC project is using RESNET as a subcontractor and is involved in upgrading the way in which contractors do their work. NSTAR has a project on model delivery systems.

- Documentation of Critical Failure Points in the Process of Implementing Energy Efficiency in Homes - PNNL is conducting a study with Portland State University and Energy Trust of Oregon on data outliers. ARBI is working on performance guarantees. BSC has a relevant project with National Grid. ORNL/TVA has a study on 10 deep energy retrofits with insight into failure points. BetterBuildings is also addressing this topic.

- Technical Solutions and Best Practices in Field Guides Developed for Different Climate Zones - NELC is doing work in this area. The EERE clearinghouse hotline is operated by WSU and gets a host of inquiries. They have an extensive database that could be evaluated. CARB has relevant work on remediation (also weatherization program experience on this issue).

- Plans of Staged Energy Upgrades for Homeowners - there is a CEER project on expert system and prioritization.

- Market Research about Motivations, Drivers, and Needs of Various Audiences - there is an overall BTP effort to identify audiences. BB is also addressing this issue. 
- Training Requirements and Training Materials Development - NREL has work in this area that is focused on weatherization. DOE has the workforce guidelines effort. There are BPI and RESNET efforts in this area as well.

- Business Model Review of Other Retrofit Programs - BetterBuildings and utility programs have a lot of knowledge in this area. NAHB-RC has a project that addresses this, to some degree. BIRA has a utility model peak reduction study in new construction that could transfer over.

- Open Data Repositories to Create Energy-use Averages - BetterBuildings is collecting data, and there is an NREL project on utility data and characteristics.

- Point-of-Use Training and Bar Codes with Installation Instructions - the DOE "apps" group is addressing this.

- “One Stop Shop” Energy Efficiency Solution for Homeowners - BIRA has several crosscutting projects that could apply to this priority. ORNL has a utility model that is appropriate. PARR has a project with CNT energy. BetterBuildings and Home Performance with ENERGY STAR are addressing this and Home Depot's code permitting project may apply (PNNL).

- Key Disconnects Between the Heat Pump Industry and Homeowners Perceptions of Issues, Terminology, and Metrics - The BA-PIRC ("Ground Source Heat Pump Evaluation in Hot Climates" and "Optimization of Hybrid Air Source Heat Pump with Gas-Fired Forced Air Furnace Backup") tasks are being delayed and should be removed. There is a heat pump program for Portland Electric that may have lessons learned. NAHB-RC has projects with Southface that may be relevant.

- Avenues for Realtors and Appraisers to Learn about the Benefits of Energy Efficient Homes and a Standard Method of Presenting this Information - BIRA is focusing on the appraisal process and Navigant has a DOE-funded study that addressed a process for appraisers. Also, EcoBroker is addressing this issue.

- Software That Can Rapidly Analyze Structures in the Field - EarthAdvantage studies should be evaluated along with Home Energy Savers. WSU with PNNL is doing some work on military family housing that may apply. The PNNL codes program focused on baseline code software and making mobile app checklists may be relevant. ARBI is working with California CSI to develop a retrofit BEopt product.

- Certification Procedures for Energy Efficiency Software Tools - it was suggested to move the entire priority to the Analysis Methods and Tools STC.

- Different Delivery Mechanisms for Messaging and Delivering Information - BARA is working on effective communication of energy efficiency research results. ARBI is piloting and evaluating different outreach and messaging techniques.

- Simple Educational and Marketing Campaigns/Materials Aimed at Consumers BetterBuildings is active in this area.

- Consistent Messaging, Standards, and Requirements Across Programs - PNNL strategic communications planning process, BetterBuildings, and Home Performance with ENERGY STAR are all addressing this priority. 
Other key points:

- There are implementation issues on the test home side that should be added to the priority list.

- BA needs a concise list of BetterBuildings activities.

- There is a problem with multiple sources of information and confusion in the market as to proper sources and validity of information; addressing this issue should be a priority. 


\section{Analysis Methods and Tools}

Ben Polly (NREL), chair of the Analysis Methods and Tools STC, presented on current STC priorities and asked for suggestions from the audience on items missing from the prioritization and project list.

The following list contains any key priorities, missing projects, and next actions identified during the session. For complete details and status on priorities of this STC, please see the presentation.

Empty Cavity Walls - Further examination and consolidation of data from Europe is needed. Data for steel-framed walls with empty cavities may also be needed.

- Ground Source Heat Pumps - Fraunhofer Solar in Germany has been researching this; there's a lot of data as they have been tracking this since 2006. Also work is being done at Oklahoma State University.

- Data Transfer Standard - ASHRAE Standard 205 (under development) will partially address this topic.

- Sensitivity Analysis - Should be coordinated with and inform validation efforts. ORNL is currently doing a sensitivity analysis with Zebra Lines Homes.

- In Situ Performance of Air Conditioners - Check database of faults in Pacific Northwest and California.

- Supplemental Dehumidification in BEopt - GTI has been doing performance mapping through PNNL looking at regeneration of desiccants and renewable sources. WSU is looking at fireplaces but have very limited tools. Supplemental humidification modeling is a related need. Relates to overall need for accurate moisture balance modeling. Comparisons of EnergyPlus to WUFI may be useful. Forthcoming "Functional Mockup Interface" capabilities in EnergyPlus may be useful.

- Enhanced Training and Education for Building America Analysis Tools - BARA recently completed BEopt training modules, which are available at BEopt.nrel.gov.

- Multifamily Window-to-Wall Ratios - NSTAR is working on multi-family characterization in Minnesota over the next 18 months (state funded). BSC is also working on multifamily units, as is NAHB-RC/Southface. A form should be created that defines the information that needs to be collected and this should be sent to the teams.

- Accuracy Tests Based on Existing Empirical Data sets - PNNL has two side-by-side lab manufactured homes that will collect qualitative data. ORNL/Zebra Lines Homes is conducting an evaluation of EnergyPlus. LBNL has several relevant projects.

- Heat Pump Water Heaters - ORNL is monitoring heat pump water use with Zebra Line Homes. A report from GTI focuses on laboratory testing of about four or five generic water heaters. These were done with standards. NREL is conducting simulation studies across climates. Fraunhofer has significant data.

- Storm Windows - Define scope: both indoor and outdoor units? Consider low-e and solar spectrally selective units. Fraunhofer has research that can support this and address 
leakage rate. BIRA also has projects focused on air leakage. Need to track NFRC rating process for storm windows. 


\section{Testing Methods and Protocols}

Dane Christensen (NREL), chair of the Testing Methods and Protocols STC, presented on current STC priorities and asked for suggestions from the audience on items missing from the prioritization and project list.

The following list contains any key priorities, missing projects, and next actions identified during the session. For complete details and status on priorities of this STC, please see the presentation.

- Method to Actively Measure Flow of Mini-split Heat Pumps in the Field - CARB is working on mini-splits for measuring airflow. ORNL is measuring mini-splits in the field as well as BIRA and IBACOS. CEER is working in this area.

- Data Logger with Increased On-Board Memory - BA-PIRC has done some work on monitors.

- Room Airflow Measurement - there is a current ASHRAE project underway at the University of Austin, Texas. IBACOS has projects in this area.

- Monitoring and Measuring Gas Flow - FSEC and ARBI both have significant projects in this area, and the University of Washington is doing some testing. PNNL has looked at measuring the flue temperature to help measure gas flow. 


\section{Meeting Action Summary}

Christine Barbour with Newport Partners asked the STCs to contribute their thoughts on actions or next steps. The following captures those comments.

- Home Energy Management - the STC encouraged participation in a meeting in Washington D.C. on December 2, 2010.

- Space Conditioning - it was noted that some gaps in this STC could transition to other committees.

- Enclosures - some gaps are going to be grouped together and the STC will work toward coordination of different efforts on cladding attachments.

- Analysis Methods and Tools - noted that the next conference call is November $15^{\text {th }}, 1: 00$ 2:00 PM Eastern time.

- Implementation - because this STC touched on projects from every team, they urged everyone to give feedback and participate while the STC is in development.

- Testing Methods - encouraged greater participation in the STC and asked that anyone who is interested or has colleagues who are interested in participating to contact the chair.

- All STC chairs will update their strategic plans by January 2012.

The audience had an open discussion as part of the meeting summary. The following captures those key comments:

- Significant comments were made about capturing and communicating the impact of the BA program.

- It was noted that BA's impact on building codes is significant and this should be explored because problems with changing code are also impediments to the implementation of BA research results. One attendee felt that it was important to show the linkage from fundamental research all the way through the code process, but to decide whether codes were the end of the process, or just the beginning.

- The audience noted that BA is a bridge between DOE, building science research, and the market. They noted that BA is about the integration of systems and strategies to whole-house, wholemarket solutions. BA does not produce widgets; it produces integrated solutions. It was suggested that focusing on "innovations" may create the wrong message, and alternate wording was discussed. It was also pointed out that the building industry is risk averse, and focusing on innovations may give the flavor of untested systems and solutions. This is absolutely not the point of BA, which has made it so innovations could be proven in the industry before production use. It was also suggested that BA's impact on the ENERGY STAR program be explored, along with impact on ASHRAE standards and other like scenarios.

The next Residential Energy Efficiency Meeting is scheduled to be held on February 29-March 2, 2012 in Austin, Texas, in conjunction with the annual RESNET conference. 
EERE Information Center

1-877-EERE-INFO (1-877-337-3463)

www.eere.energy.gov/informationcenter

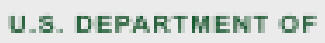
ENERGY

Energy Efficiency \& Renewable Energy 